\title{
DYNAMIC AND STATIC SHAPE TEST/ANALYSIS CORRELATION OF A 10 METER QUADRANT SOLAR SAIL
}

\author{
Barmac K. Taleghani ${ }^{1}$ \\ NASA Langley, Army Research Laboratory, Hampton, VA \\ Peter S. Lively ${ }^{2}$ \\ Lockheed Martin Space Operations, Hampton, VA \\ James L. Gaspar ${ }^{3}$ \\ NASA Langley Research Center, Hampton, VA \\ David M. Murphy ${ }^{4}$ and Thomas A. Trautt ${ }^{5}$ \\ ATK Space Systems, Goleta, CA
}

\begin{abstract}
This paper describes finite element analyses and correlation studies to predict deformations and vibration modes/frequencies of a 10-meter quadrant solar sail system. Thin film membranes and booms were analyzed at the component and system-level. The objective was to verify the design and structural responses of the sail system and to mature solar sail technology to a TRL 5. The focus of this paper is in test/analysis correlation.
\end{abstract}

\section{Introduction}

$\mathrm{E}$ FFICIENTLY propulsive solar sails are ultra low mass (gossamer) space structures which can be used for long duration missions. Solar sails have low thrust but require no fuel which allows them to accelerate for the entire life of the mission using the Sun's photons. ${ }^{1,2}$ Due to their favorable mass and packaging size they are advantageous technology for advanced missions. ${ }^{3}$ Solar sails require enormous sail area to make the design efficient while being as lightweight as possible. Such gossamer structures are difficult to design and analyze. These solar sails are both highly compliant and extremely nonlinear in structural response.

Adding to these difficulties is the fact that solar sails proposed for space missions are impossible to fully test on the ground. While large sails could easily endure the pressure of sunlight in space, they would fail if loaded under their own weight when tested on the ground. To assess the accuracy of analytical models in order to efficiently predict their static and dynamic behavior of large sails, smaller solar sails are analyzed and tested. This builds experience and confidence that the modeling techniques are adequate to predict the behavior of the larger space-bound sails.

While some prior work on FEA predictions of the dynamics of solar sail systems ${ }^{4}$ has been published, work in this area has been limited. Most sail system papers include primarily design and closed-form analysis studies. $^{5-7}$ The focus of this paper is to discuss results of finite element analysis and, more importantly, test/analysis correlation activities performed on a 10 meter solar sail test article. The static and ground vibration tests were conducted in NASA Langley's 16 meter vacuum chamber. Prior to testing, a preliminary analysis was performed to evaluate proper test conditions and to determine sensor and actuator

\footnotetext{
${ }^{1}$ Sr. Mechanical Engineer., AIAA Member

${ }^{2}$ Aeronautical Engineer Sr., AIAA Member

${ }^{3}$ Research Engineer

${ }^{4}$ Chief Research Engineer

${ }^{5}$ Research Engineer
} 
locations. After testing was completed, an analysis of each test configuration was performed. Post-test model refinements include updated properties that accounts for sensors, wiring, and other components used for testing. This paper's primary goal is to describe the development of finite element models and test/analyses correlation using MSC.Nastran. ${ }^{8,9}$ Comparison with parallel analyses carried out using an alternate software program, ANSYS ${ }^{10}$, are also reviewed.

\section{Test Configuration and Results}

The solar sail test article Figure 1 is a single quadrant of a 10 meter solar sail system and consists of a central hub structure, two self-supporting booms, and a solar sail membrane. The triangular sail membrane is made from aluminized CP1 material and features stiff cords embedded along the edges. The cords connect to the sail area by means of a shear compliant border that is designed to reduce

Figure 1. Finite element model of the 10 meter system. wrinkling of the membrane.

The sail triangular membrane connects to the hub at the interior corner by a tack line, and connects to the boom tips via halyards. Loads on the membrane are measured by a load cell on the tack line with the tension applied at the halyard lines.

Three types of testing were conducted. The sail membrane was tested statically without the booms and
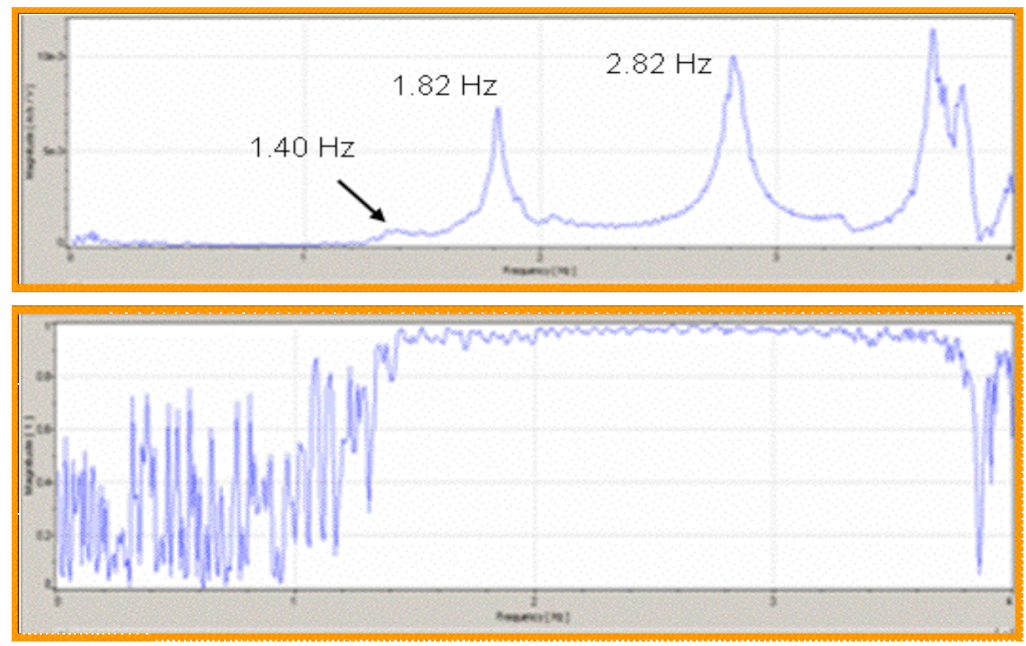

Figure 2. FRF and Coherence for 10 meter system with 2.36 lbs. tack line load.

American Institute of Aeronautics and Astronautics 
supporting structures. The booms were tested dynamically without the sail attached, both component tests conducted in ambient conditions. The complete system was tested for dynamics in vacuum.

\section{A. System Vacuum Testing}

Measurements were made at 31 retro-reflective targets evenly distributed across the sail. To assess membrane dynamics The baseline test ${ }^{11,12}$ consisted of excited each of the three sail corners with electro-magnets. The magnets were driven with a slow sine sweep with each magnet actuated in-phase or out-ofphase to one another to capture the lowest frequency and modes for finite element correlation. All sail membrane dynamics tests were perform in a 1 Torr vacuum.

The first four sail membrane modes were properly identified via in-vacuum modal tests with very clean Frequency Response Functions (FRFs) shown in Figure 2 and high coherences $(\mathrm{COH})$ at resonance. Mode shapes looked smooth, symmetric, and correlated well with pretest predictions. The first mode was obtained with the two magnets at the

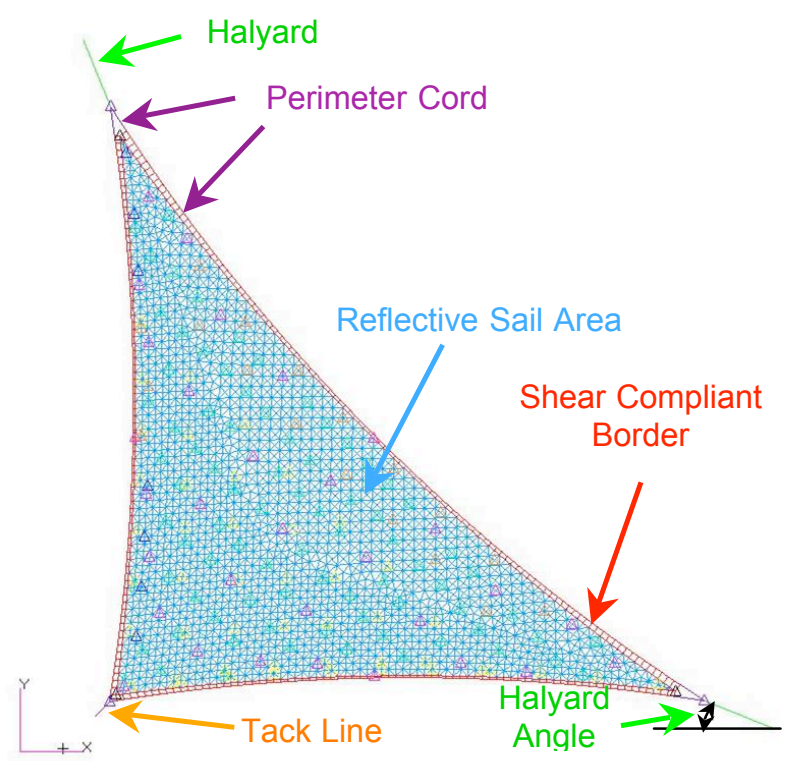
measurement precision ( 1 sigma) with this camera configuration is 0.017 inches in $\mathrm{X}$ and $\mathrm{Y}$, and 0.022

Figure 4. Sail components overview.

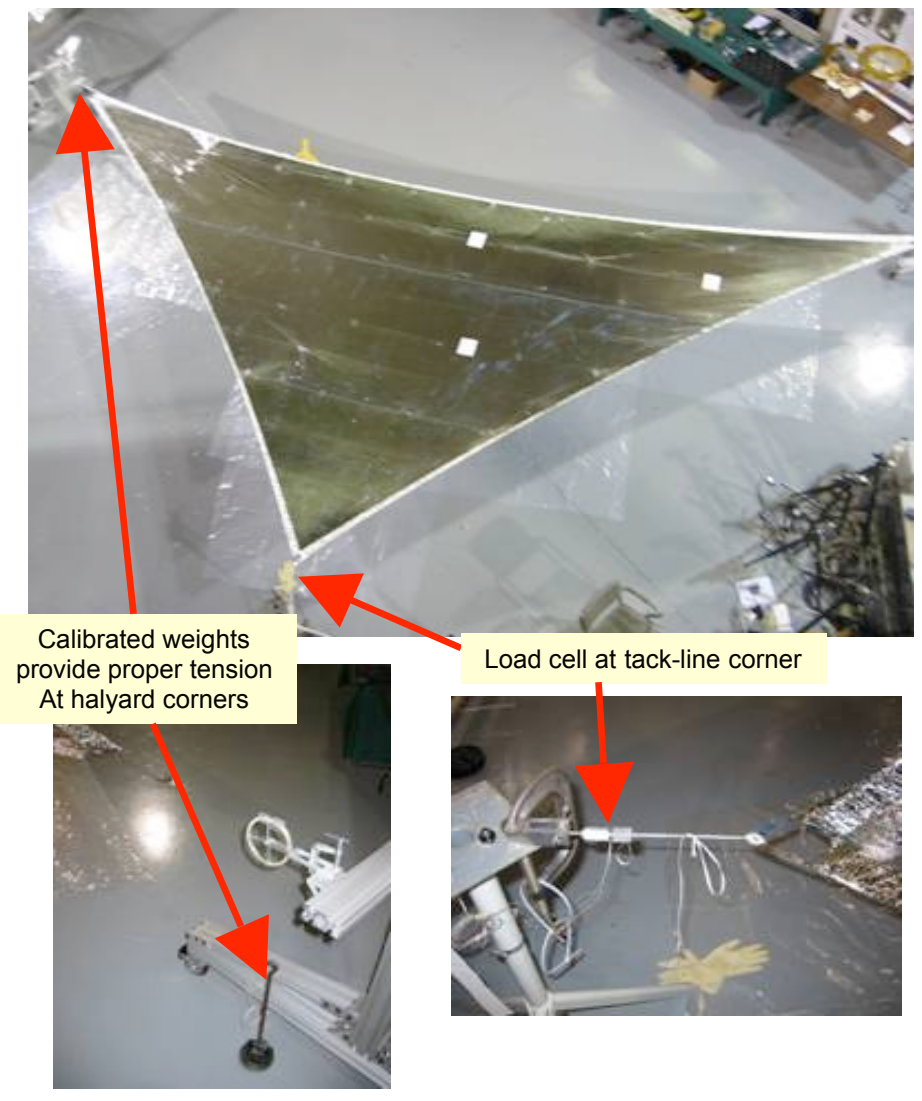

Figure 3. Laser Radar Measures Sail Membrane Shape in Ambient Atmospheric Conditions.

halyard corners driven in-phase by a slow sine sweep. Modes 2 and 4, were obtained with the halyard corner magnets driven outof-phase. While, mode 3 was obtained in a separate test with only the magnet at the tack-line active during the sine sweep.

Videogrammetric model deformation (VMD) was performed to measure the sail shape in the in-vacuum test configuration, with single frame data being used for static measurements. Three cameras were used for this purpose, located approximately 10-m above the sail around its perimeter. Cameras used in LaRC facility are digital video cameras mounted inside vacuum canisters with 2 Mega Pixel monochrome resolution, 30 frames per second speed, 10 times zoom lens, pan-tilt capability, and digital recording functions. All cameras used the same one-inch retro-reflective targets as the laser vibrometer. The inches in $Z$. The maximum sail displacement occurred near the center of the sail geometry, with a 4.73 inch 
displacement relative to the tack-line corner location for a $2.5 \mathrm{lb}$ tack-line load.

In addition to the complete system, components were tested using two secondary test setups.

\section{B. Boom Ambient Tests}

The first component test was a dynamic test of the booms in ambient atmospheric conditions, where the sail was detached but the rest of the system remained. Boom tip responses were measured with the laser vibrometer at retro-reflective targets measuring vertical motion at the two upper longerons, and one retroreflective target measuring lateral motion at the lower longeron. The vertical, lateral, and torsion modes were properly identified for each boom. The FRFs and coherence were excellent. ${ }^{12}$

\section{Membrane Ambient Test}

The second component test setup was for a static test of the solar sail membrane in ambient atmospheric conditions without the booms or secondary support structure as shown in Figure 3. The membrane had to be tested in this manner due to thermal currents that developed in the vacuum chamber. Due to scheduling issues, the three tack line load cases were not tested concurrently, with the nominal case $(2.5 \mathrm{lbs}$. tack line load) tested first and the off nominal cases tested after dynamic testing in the vacuum chamber was completed.

The static deformation test was performed with a Leica Laser Radar system mounted approximately 10$\mathrm{m}$ above the sail and the membrane was supported by applying tension to the three corners of the sail. The shape was measured over the entire sail with lines running parallel to the long sail edge. Scan lines were spaced 3 inches apart and the point spacing within the line of 0.02 inches. With this setup displacement accuracy was approximately 90-microns. Results showed that the maximum sail displacement occurred near the center of the sail geometry, with a 6.65 inch displacement relative to the tack-line corner location for a $2.5 \mathrm{lb}$ tack-line load. This is different than the one measured with VMD in-vacuum for the identical load case. Upon further investigation, it was determined that the difference is attributable to differences in halyard angle at the boom tips between the tests. The in-vacuum test with VMD was identified to have the proper halyard angle for use with finite element model correlation.

\section{Solar Sail Modeling}

The 10 meter solar sail system was modeled in two discrete parts. The first is the actual solar sail and the second part is the support structure which includes the booms, central hub and the underlying supports. An overview of the model can be seen in Figure 1. This model was generated using MSC.PATRAN and run within MSC.NASTRAN nonlinear solution 106.

For the static shape measurements only the sail portion of the model is analyzed (except for the VMD case) since the sail was removed from the system for billow measurements. The sail portion of the model shown in Figure 4 is made up of halyard and tack lines, cord elements, the main sail area and the shear compliant border. The shear compliant border is modeled as an orthotropic material that allows transmission of stresses perpendicular to the edge of the sail, but is compliant in the transverse and shear directions.

The finite element model of the quadrant sail consisted of 5435 structural elements (CQUAD4, CTRIA3, CBEAM,) and 2856 nodes. In addition there are 218 point masses which represent sensor targets, sequencers which are used for deployment, grommets, and doublers. All these point masses accounted for more than $10 \%$ of the total sail weight.

Booms, hub structure and support structure were modeled according to ABLE engineering specifications and drawings. Boom design shown in Figure 5 consists of longerons, battens diagonals

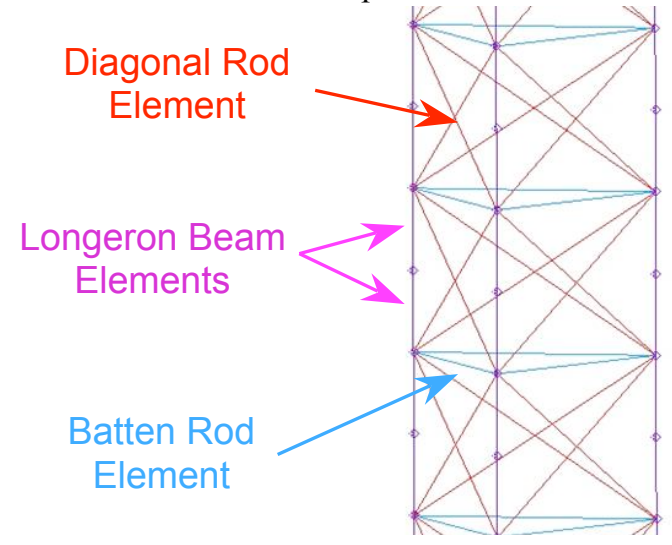

Figure 5. Boom components overview. 


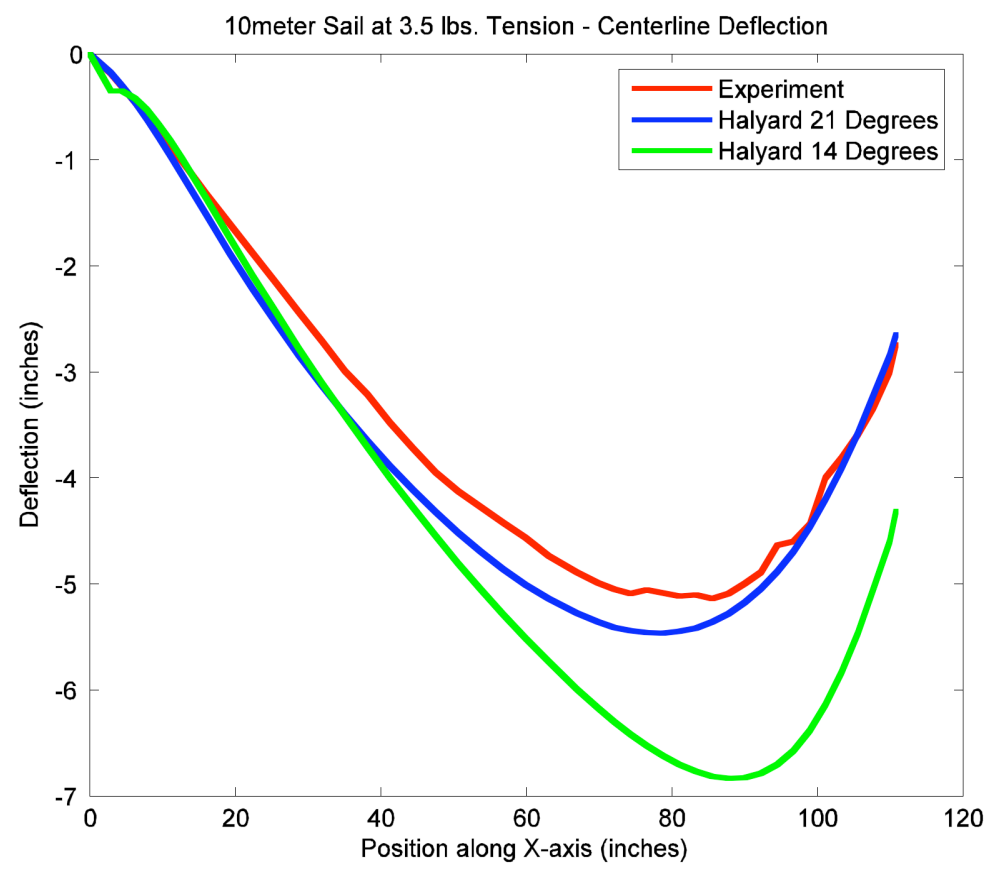

Figure 6. Analytical prediction for the 10-meter sail with the nominal halyard angle, 21 degrees, and initial halyard angle estimate of 14 degrees, compared to experimental results.

and point masses to represent the fittings, wiring and sensors. The diagonals are pretensioned and modeled as tension only elements. Connecting the booms to the sail was achieved using a tip structure consisting of beam elements and point masses to represent the actual structure.

Other components of the model include a central hub and an underlying support frame. The central hub is a paneled box that supports the roots of the booms and connects to the underlying support frame. The support frame consists of aluminum beams, which are connected to the central hub and the ground.

Models developed in ANSYS were constructed similarly, with the most significant difference occurring
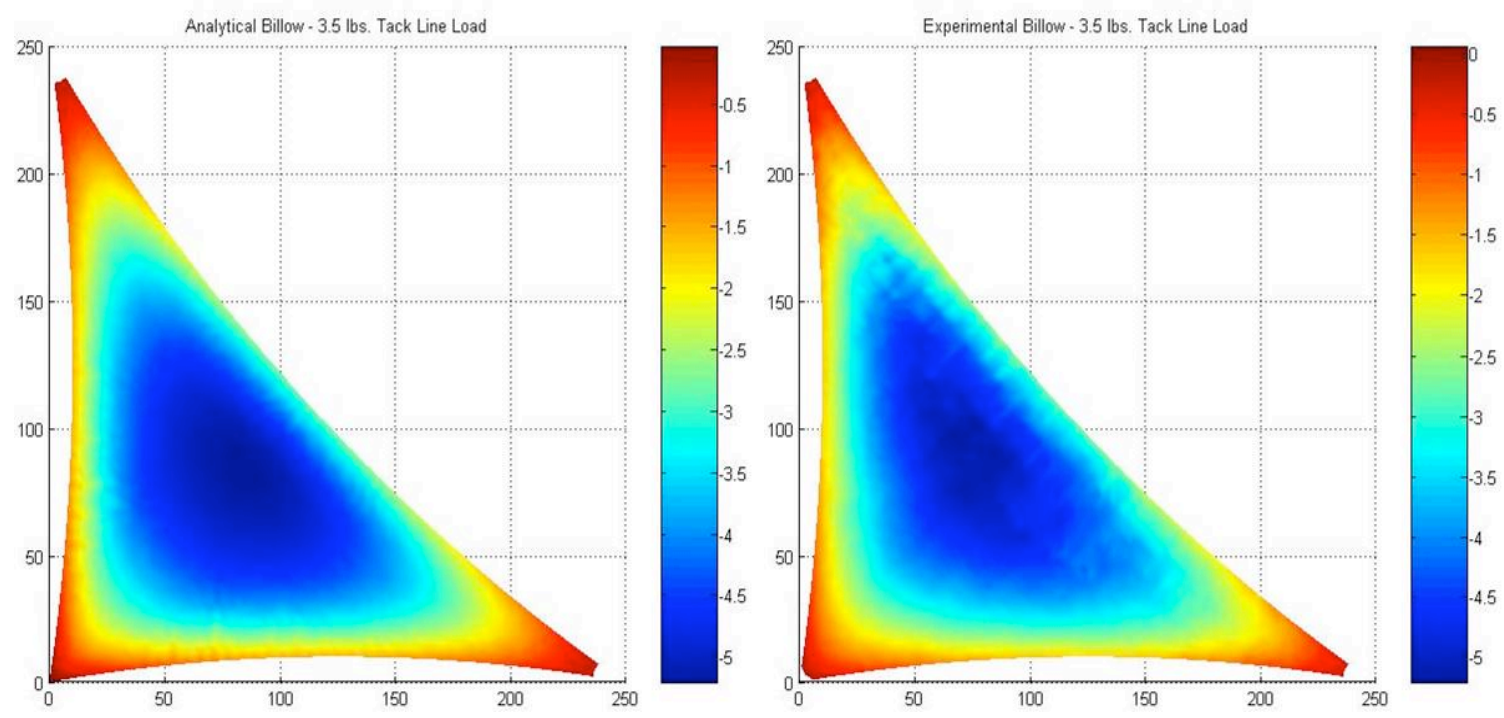

Figure 7. Analytical billow prediction vs. experimental billow result for the 10-meter solar sail with 3.5 lbs. tack line load (in inches). 
in the specific elements chosen for sail border modeling and pre-stress to the sail was developed through thermal contraction of halyard lines. To simulate a fully shear-compliant border, individual link elements (tension only) were placed along the cord to connect to the main sail element nodes.

\section{Comparison of Test/Analysis Results}

The finite element model predictions for the 10 meter solar sail system were in agreement with the test results. The FEM prediction of the static sail billow was within an inch of the test results. The comparison of dynamic results also showed good agreement between test and analysis. All four tested mode shapes showed a good quantitative comparison to analytical modes. The first mode showed especially good correlation, in both shape and frequency.

\section{A. Static Shape Analysis}

For the static shape analysis only the sail portion of the FEM model was used. The analytical results are compared to the Leica laser radar test data. The Leica spatial resolution is denser than the data from the finite element model, therefore the data was mapped onto the finite element nodes for ease of comparison. Additionally the experimental and analytical data was transformed so that the three corners of the sail lay in the $x-y$ plane and the two halyard corners are symmetrically aligned. This allows for more accurate mapping of the Leica data to the FEM grid and to concentrate the data comparison on the billow.

Because the static shape tests were not performed concurently, the test setup varied slightly between tests. Additionally, during the test setup the halyard angles were not set to the nominal halyard angle of 21 degrees.

Initially the halyard angle was estimated to be 14 degrees during testing for the $2.5 \mathrm{lbs}$ load case. The new halyard angle was used in the analysis of static shape for all three load cases. After detailed review of the results it was determined that the angle for the $1.5 \mathrm{lbs}$. and $3.5 \mathrm{lbs}$. load cases was 19.5 degrees. There was not enough data for

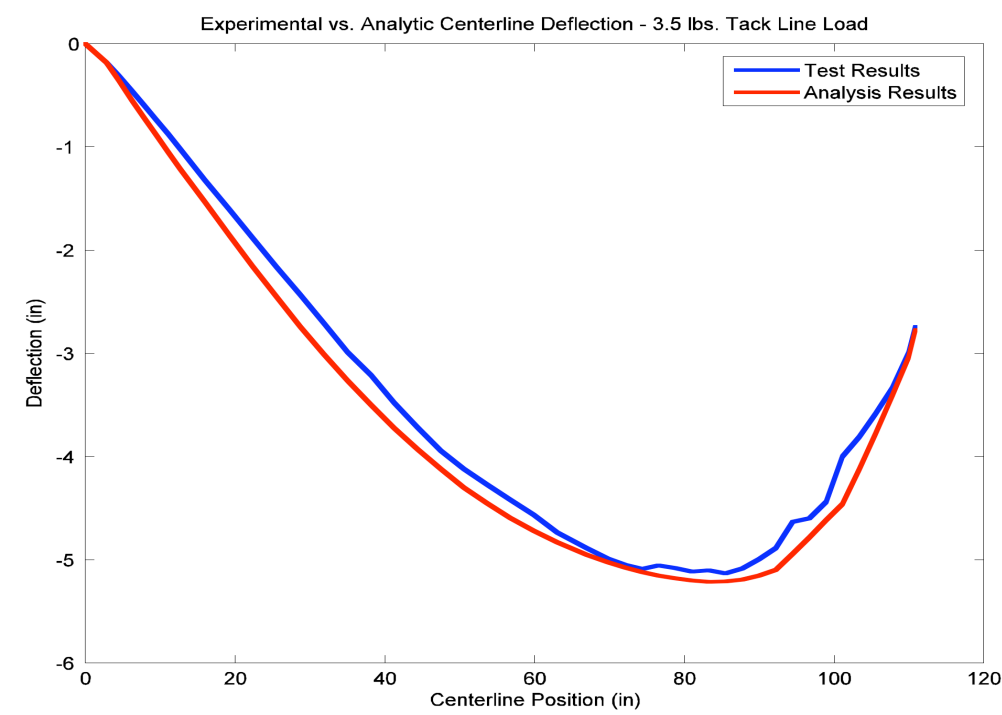

Figure 8. Comparison of experimental centerline deflection vs. analytic prediction for the $3.5 \mathrm{lbs}$. tack line load case.

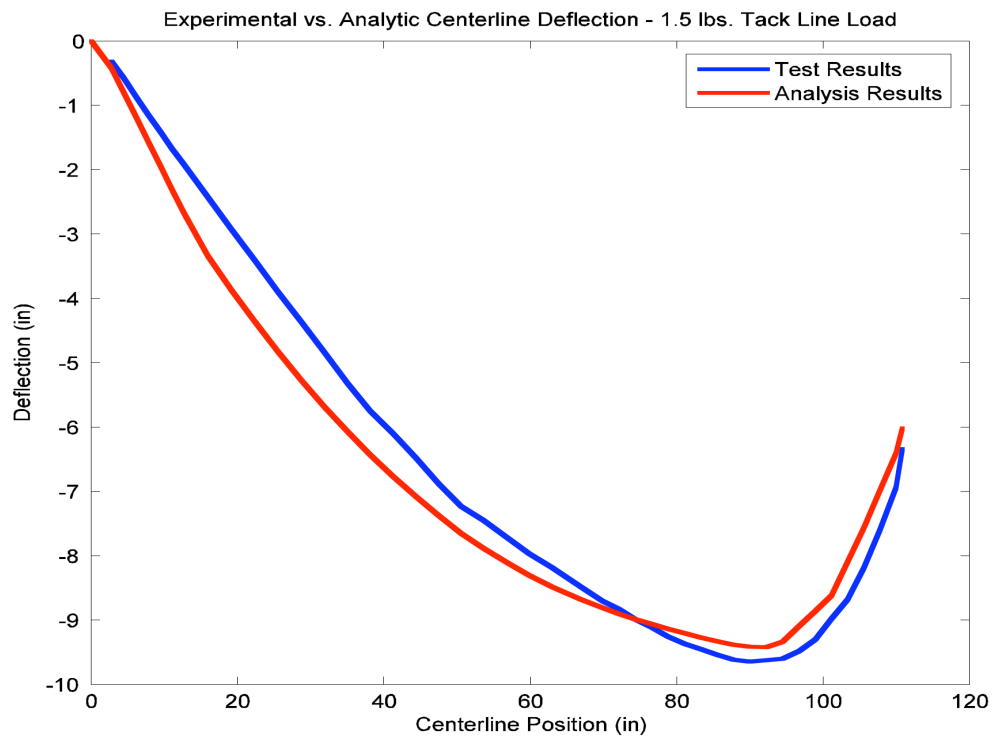

Figure 9. Comparison of experimental centerline deflection vs. analytic prediction for the $1.5 \mathrm{lbs}$. tack line load case. 
the $2.5 \mathrm{lbs}$ load case to calculate a halyard angle, so it was analyzed at the nominal (21 degrees) halyard angle.

The difference in halyard angle has a profound effect on both the magnitude and the shape of the billow. The 3.5 lbs. load case was analyzed at both 14 degrees and at the nominal 21 degrees. The centerline deflection (from the tack line corner to the center of the long edge) results of the $3.5 \mathrm{lbs}$. load case can be seen in Figure 6 along with the Leica test results.

The halyard angle used for the final analysis of the 1.5 and 3.5 lbs tack line load was 19.5 degrees. For the $3.5 \mathrm{lbs}$. tack line load case, the experimentally measured sail billow of 5.19 inches compares well to the analytical result of 5.21 inches.

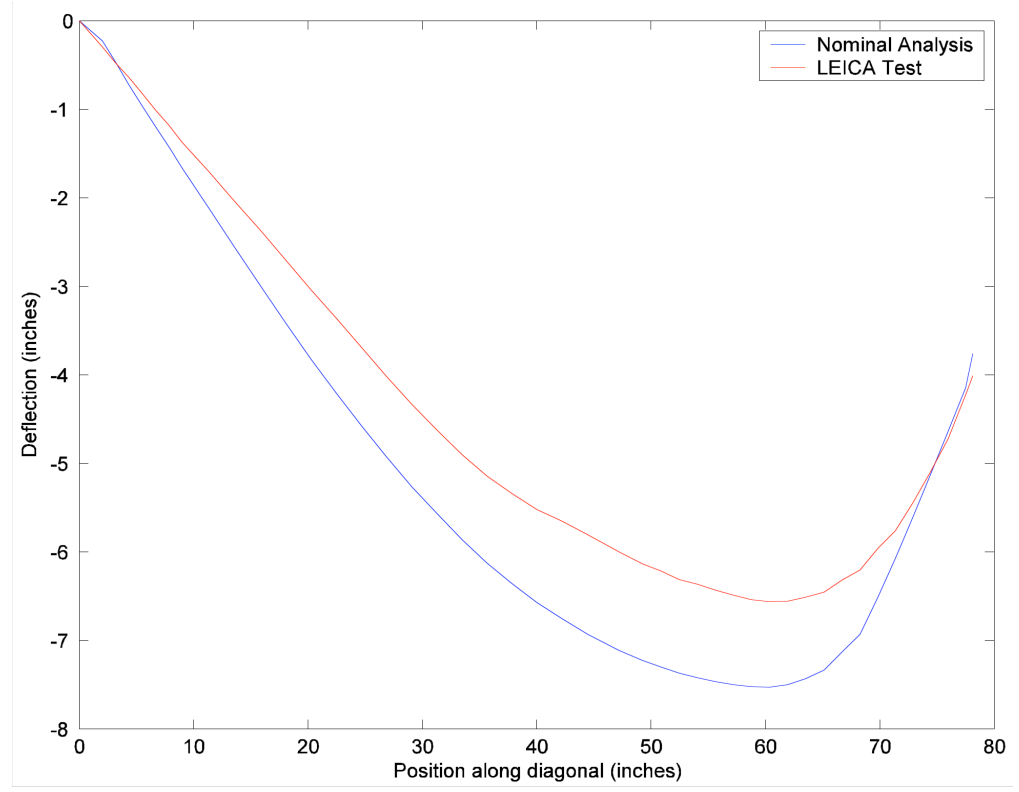

An overall view of the deformation shape for both analysis and experiment can be seen in Figure 7. The centerline deflection which goes from the tack line corner to the center of the long edge of the sail is shown in Figure 8.

The $1.5 \mathrm{lbs}$. tack line load case also shows a good agreement between analysis and experiment. The analysis shows a maximum deflection prediction of 9.44 inches and the experimental result is 9.96 inches. Figure 9 shows the centerline deflections of the experiment and the analytical predictions.

The analytical prediction of the billow shape for the $2.5 \mathrm{lbs}$. tack line load with nominal halyard angles shows a maximum deflection of 7.54 inches versus a Leica deflection of 6.65 inches. The centerline deflection comparison can be seen in Figure 10.

In addition to the Leica data for the $2.5 \mathrm{lbs}$. tack line load case, there is VMD data of the sail while it was attached to the booms and support structure. Because the sail is mounted in the system the halyard angles are set geometrically and additional calculations are not needed. The FEM model reflects this by modeling the complete system (and not the sail only as is done for the Leica comparisons).

The VMD data for the 2.5 lbs. tack line load case is quite

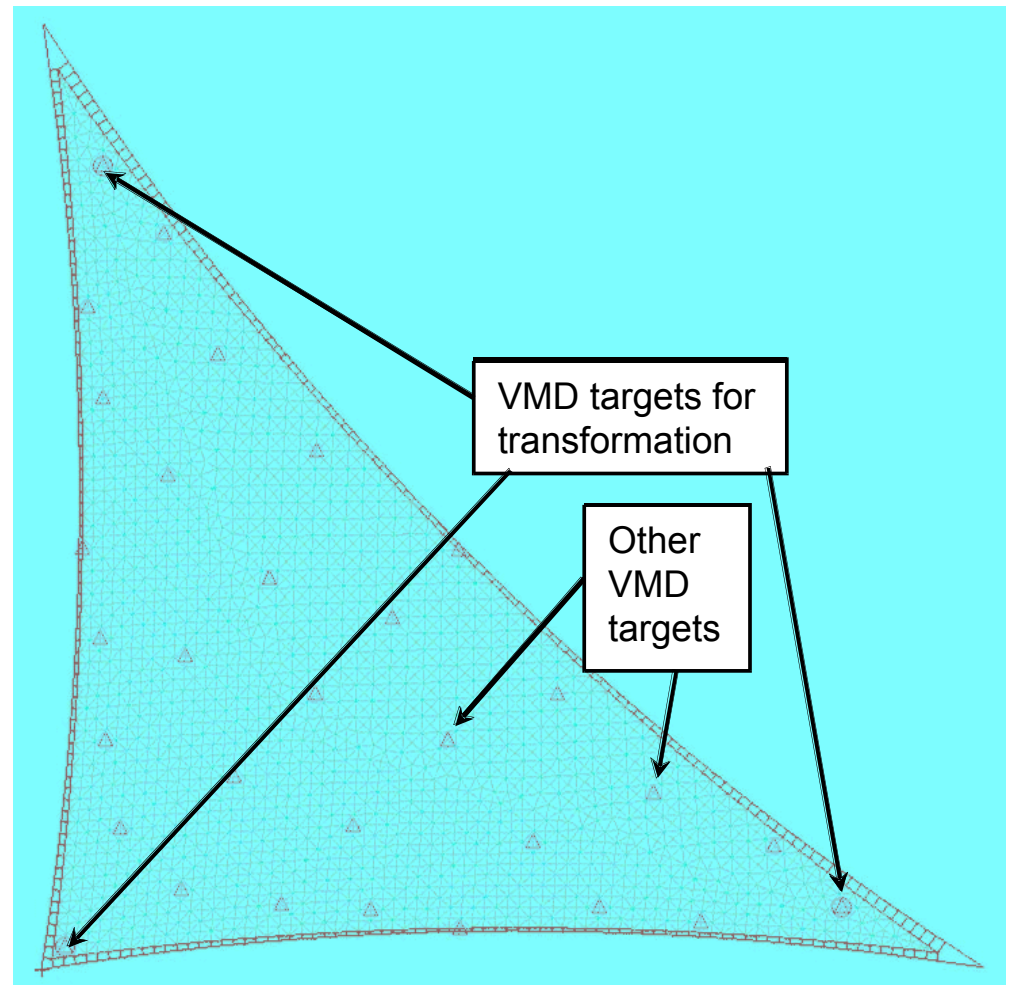

Figure 11. Distribution of VMD targets on the 10 meter solar sail. 
sparse with only 31 measurement points on the sail. Additionally, only the targets positions relative to each other are known. In order to compare the VMD results with the analytical results a transformation was performed on both sets of data. The analytical results were transformed so that the three corners of the sail lay in the $x-y$ plane. VMD results were then transformed so that the three corner VMD targets are aligned with the corresponding points on the analytical results. The target locations relative to the FEM grid are shown in Figure 11. The post transformation results are shown in Figure 12. The difference in the billow is 0.16 inches (the maximum analytic deflection is 7.93 inches relative to the system, or 6.59 inches relative to the transformed plane).

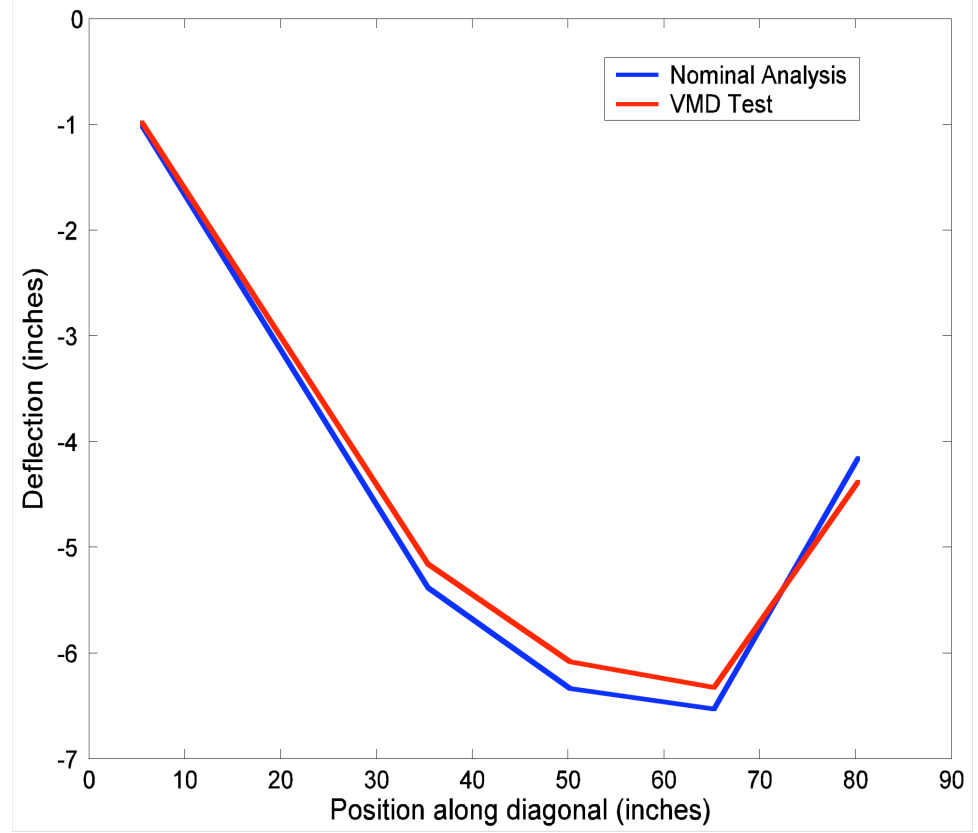

Figure 12. Midline videogrammetric results compared to analytical results for the $\mathbf{2 . 5}$ lbs. tack line load case.

\section{B. Dynamic Analysis}

Dynamic testing was performed on the boom and support structure in the absence of the solar sail. These results and the parametric studies that were conducted to tune the booms will not be presented here. However, tuned booms parameters were used in the system dynamics calculations. This was done to isolate the effects of the solar sail dynamics from the booms and support structure.

The system dynamics were nominally tested at the $2.5 \mathrm{lbs}$. tack line load case. The first, second and fourth test modes were at an actual tack line load of $2.56 \mathrm{lbs}$., and the third test mode was measured with a tack line load of $2.36 \mathrm{lbs}$.

The first mode both analytically and in test is a billow type mode. A comparison of the first experimental mode shape with the first analytical mode shape is seen in Figure 13. The experimental frequency is $1.40 \mathrm{~Hz}$ with an analytical frequency of $1.46 \mathrm{~Hz}$, which is a difference of $4 \%$.

The analytic and experimental mode shapes for the second system mode can be seen in Figure 14 and it
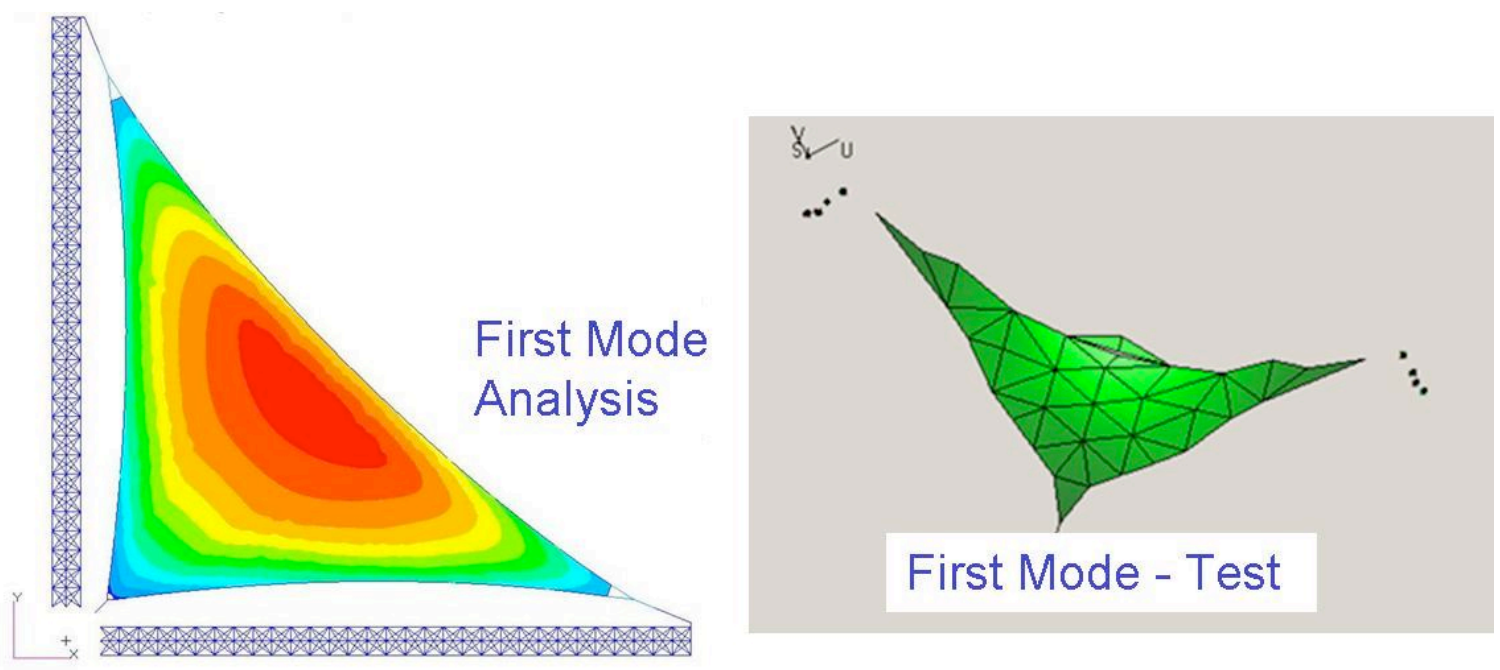

Figure 13. First mode shape for the $\mathbf{1 0}$ meter solar sail system, analytic and test results. 

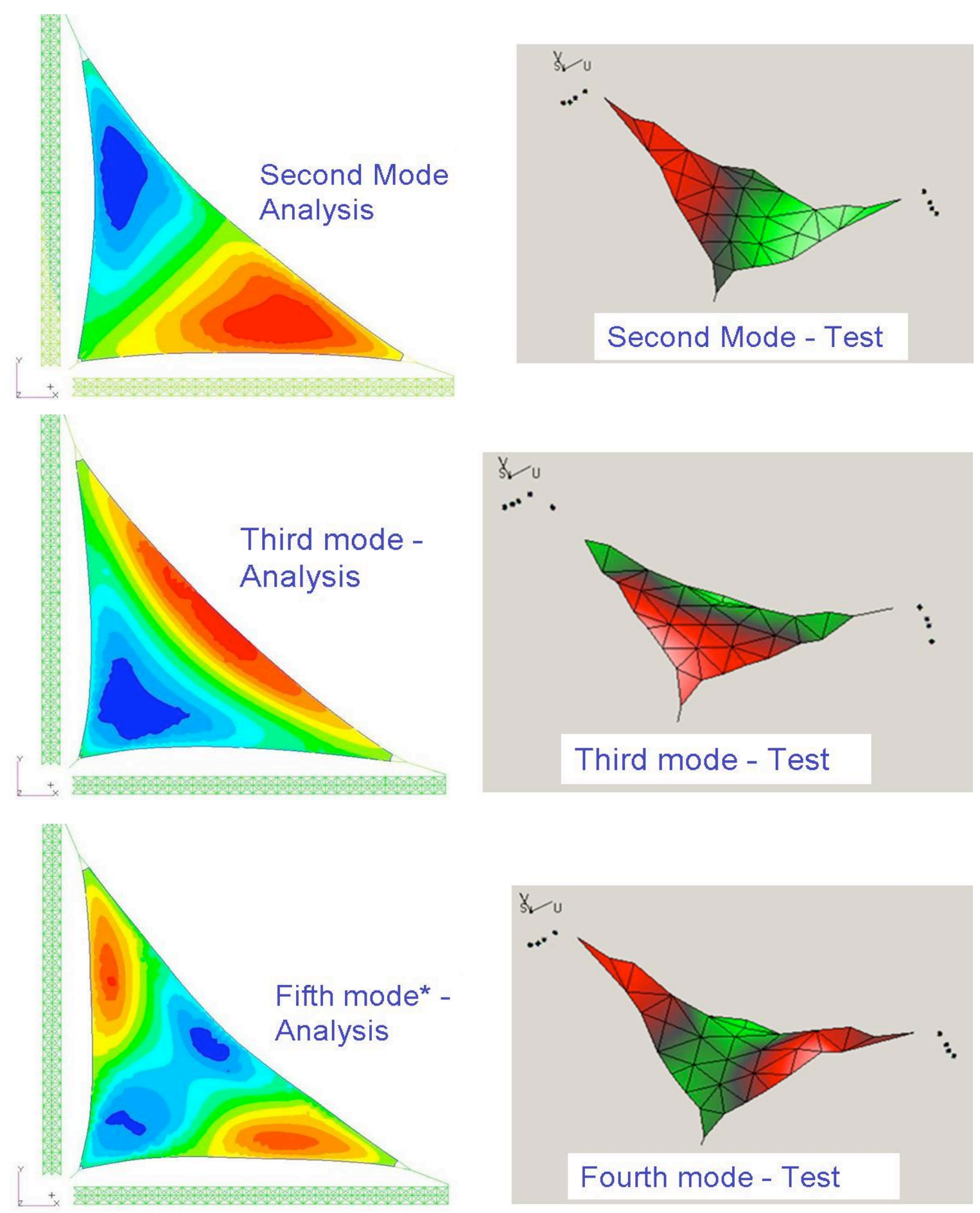

* $4^{\text {th }}$ mode of test corresponds to $5^{\text {th }}$ mode of analysis

Figure 14. Second, third and fourth test modes with comparable analytical modes.

is characterized by a side-to-side rocking motion. The analysis produced a frequency of $2.43 \mathrm{~Hz}$ and the experimental result was $1.83 \mathrm{~Hz}$. The second mode is the mode with the highest frequency error at $33 \%$.

The third mode is shown in Figure 14 and is characterized by an inboard-outboard rocking motion. The analytical frequency for the third mode is $2.67 \mathrm{~Hz}$ and the test result was $2.23 \mathrm{~Hz}$ (20\% error). 


\begin{tabular}{|c|c|c|c|c|}
\hline $\begin{array}{c}\text { Mode } \\
\text { Number* }\end{array}$ & $\begin{array}{c}\text { Tack Line } \\
\text { Load (lbs) }\end{array}$ & $\begin{array}{c}\text { Test } \\
(\mathrm{Hz})\end{array}$ & $\begin{array}{c}\text { Analysis } \\
(\mathrm{Hz})\end{array}$ & Error (\%) \\
\hline 1 & 2.56 & 1.4 & 1.46 & 4 \\
\hline 2 & 2.56 & 1.82 & 2.43 & 34 \\
\hline 3 & 2.36 & 2.23 & 2.67 & 20 \\
\hline 4 & - & - & 3.17 & $\mathrm{n} / \mathrm{a}$ \\
\hline 5 & 2.56 & 2.82 & 3.46 & 23 \\
\hline
\end{tabular}

* Mode number corresponds to analytical mode number

The fifth analytic mode is a good match for the fourth experimental mode, as can be seen in Figure 14. The analysis shows a frequency of $3.46 \mathrm{~Hz}$ and the experimental result is $2.82 \mathrm{~Hz}$ ( $22 \%$ error).

\section{Table 1. Frequency comparison of experimental and analytical system modes.}

The fourth analytic mode is an in-plane mode, which cannot be detected with the laser vibrometer and is very difficult to excite experimentally. A comparison of the above results are shown in Table 1.

\section{Comparison to ANSYS Results}

A number of parallel analyses were also carried out using the finite element analysis in ANSYS. A comparison of the results for system frequencies, shown in Figure 15, illustrates the findings obtained with

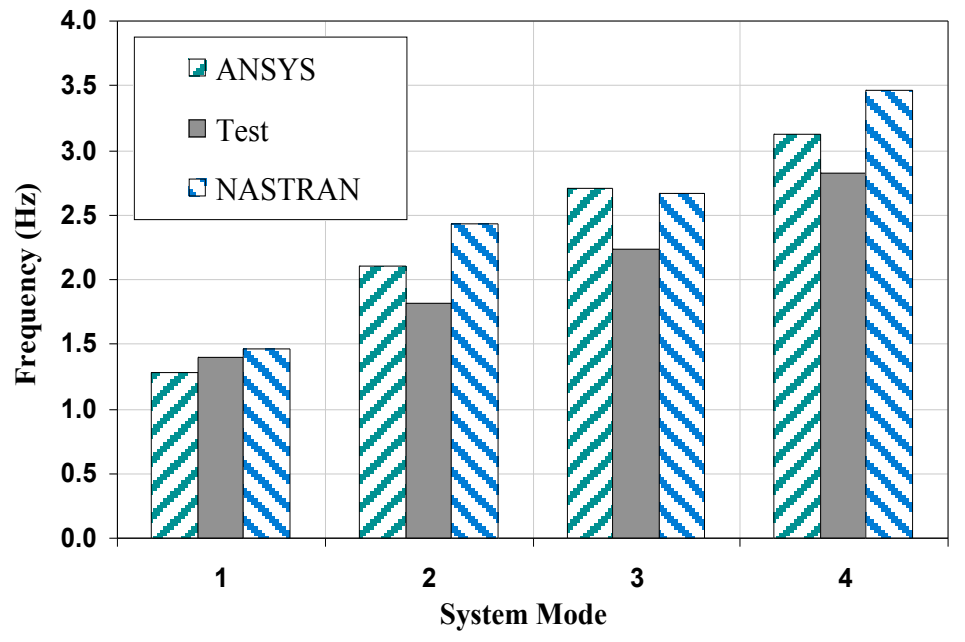
ANSYS are similar to the NASTRAN results. In addition Figure 15. Comparison of FEA Predictions to system mode this activity demonstrates that frequencies in test.

these novel analyses can be accomplished with more than one commercially available software program, but not without employing specific model construction techniques learned through significant trial and error. The lessons learned in the development of efficiently convergent models for these solar sail systems in the two FEA programs were complimentary and are being carried forward in the predictions for larger systems currently in preparation for test.

V.

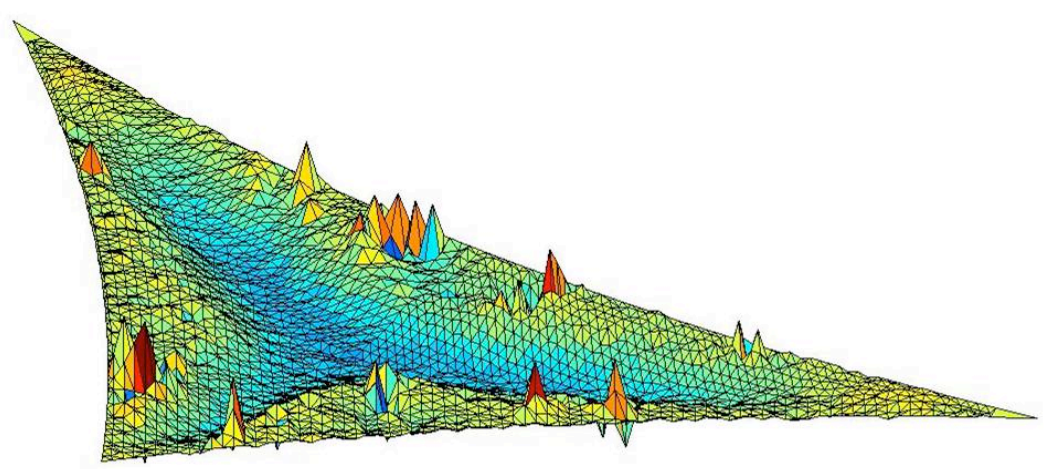

Figure 16. Change in sail billow due to reduction of CP1 stiffness by $50 \%$. 


\begin{tabular}{ccc|c|c|c|c}
\hline & \multicolumn{5}{c}{ Modal Frequencies (Hz) } \\
$\begin{array}{c}\text { Mode } \\
\text { Number }\end{array}$ & Test & $100 \%$ & $75 \%$ & $50 \%$ & $25 \%$ & $10 \%$ \\
1 & 1.40 & 1.456 & 1.453 & 1.449 & 1.440 & 1.419 \\
\hline 2 & 1.82 & 2.430 & 2.424 & 2.408 & 2.378 & 2.316 \\
\hline 3 & 2.23 & 2.674 & 2.655 & 2.619 & 2.561 & 2.499 \\
\hline 4 & NA & 3.167 & 3.166 & 3.164 & 3.159 & 3.148 \\
\hline 5 & 2.82 & 3.457 & 3.435 & 3.411 & 3.364 & 3.270
\end{tabular}

Table 2. Effect of CP1 modulus variation on modal frequencies.

\section{Parametric Studies}

After comparing test and analytical results, a number of parametric studies were conducted in an effort to improve the accuracy of the system model. In particular, the CP1 modulus, CP1 bending stiffness, and tack line length were varied to determine their effects on the system dynamics.

A certain amount of variation in the CP1 thickness and modulus is expected due to manufacturing. The CP1 material that is used for the sail's surface has numerous creases created during manufacturing, storage, and general handling of the sail. At low stress levels, it is estimated that the stiffness of CP1 might effectively be as little as a tenth of the nominal value due to the creases, before including variations due to manufacturing. In addition to reducing the effective in-plane modulus of the material, it is believed that the creases will greatly increase the effective bending stiffness by moving material away from the neutral axis.

\begin{tabular}{|c|c|c|c|c|c|c|c|c|}
\hline \multirow{3}{*}{$\begin{array}{l}\text { Mode } \\
\text { Number }\end{array}$} & \multicolumn{8}{|c|}{ Modal Frequencies $(\mathrm{Hz})$} \\
\hline & \multirow{2}{*}{ Test } & \multirow{2}{*}{$\begin{array}{l}\text { Nominal } \\
\text { Stiff. }\end{array}$} & \multicolumn{6}{|c|}{ Increase in Bending Stiffness of CP1 } \\
\hline & & & $x 10$ & $x 10^{2}$ & $x 10^{3}$ & $\times 10^{4}$ & $\times 10^{5}$ & $\times 10^{6}$ \\
\hline 1 & 1.40 & 1.453 & 1.454 & 1.454 & 1.455 & 1.465 & 1.500 & 1.581 \\
\hline 2 & 1.82 & 2.398 & 2.397 & 2.399 & 2.407 & 2.437 & 2.517 & 2.656 \\
\hline 3 & 2.23 & 2.745 & 2.746 & 2.746 & 2.736 & 2.753 & 2.755 & 2.908 \\
\hline 4 & $\mathrm{n} / \mathrm{a}$ & 3.073 & 3.073 & 3.073 & 3.073 & 3.075 & 3.076 & 3.029 \\
\hline 5 & 2.82 & 3.4318 & 3.416 & 3.425 & 3.450 & 3.505 & $\mathrm{n} / \mathrm{a}$ & 3.916 \\
\hline
\end{tabular}

Table 3. Effect of CP1 Bending Stiffness on Modal Frequencies.

For parametric studies, the CP1 modulus was varied analytically from $100 \%$ of nominal down to $10 \%$ of nominal. The effect on the dynamics of the model was not significant. Table 2 shows the frequencies for the first five modes of the system based on variations of the $\mathrm{CP} 1$ modulus. The reduction of the modulus by $90 \%$ has the largest effect on the third mode with a reduction of frequency of only $6.6 \%$. Likewise, the deflection behavior is not greatly influenced by the CP1 modulus. Figure 16 shows the change in deflection caused by reducing the CP1 stiffness by $50 \%$. The central region has an increased deflection of only 0.05

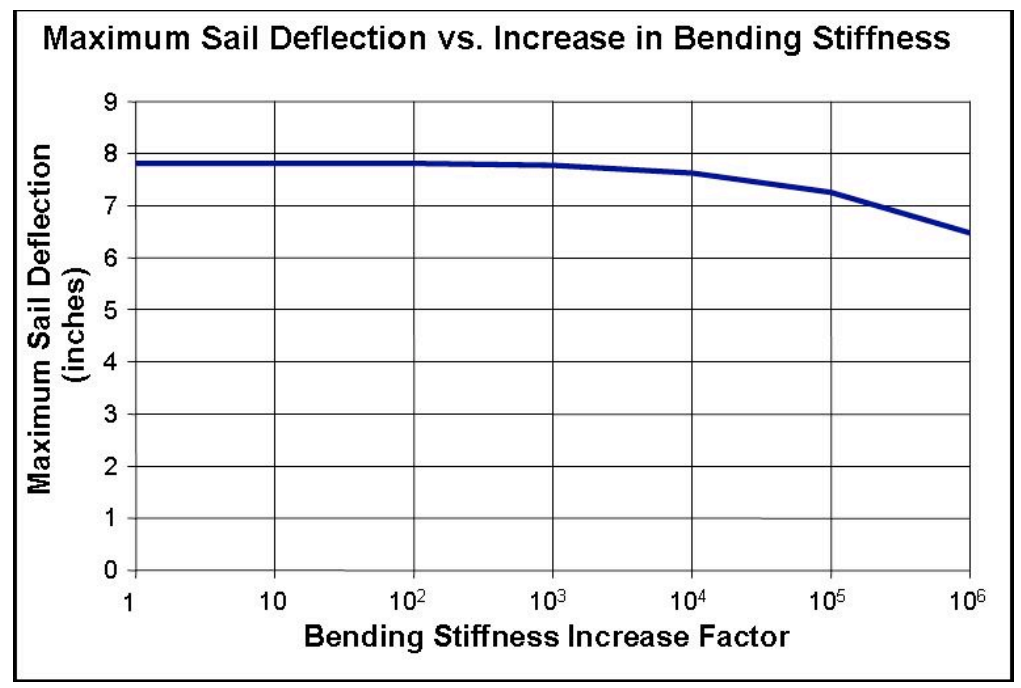

Figure 17. Effect of bending stiffness variation on maximum sail deflection. 

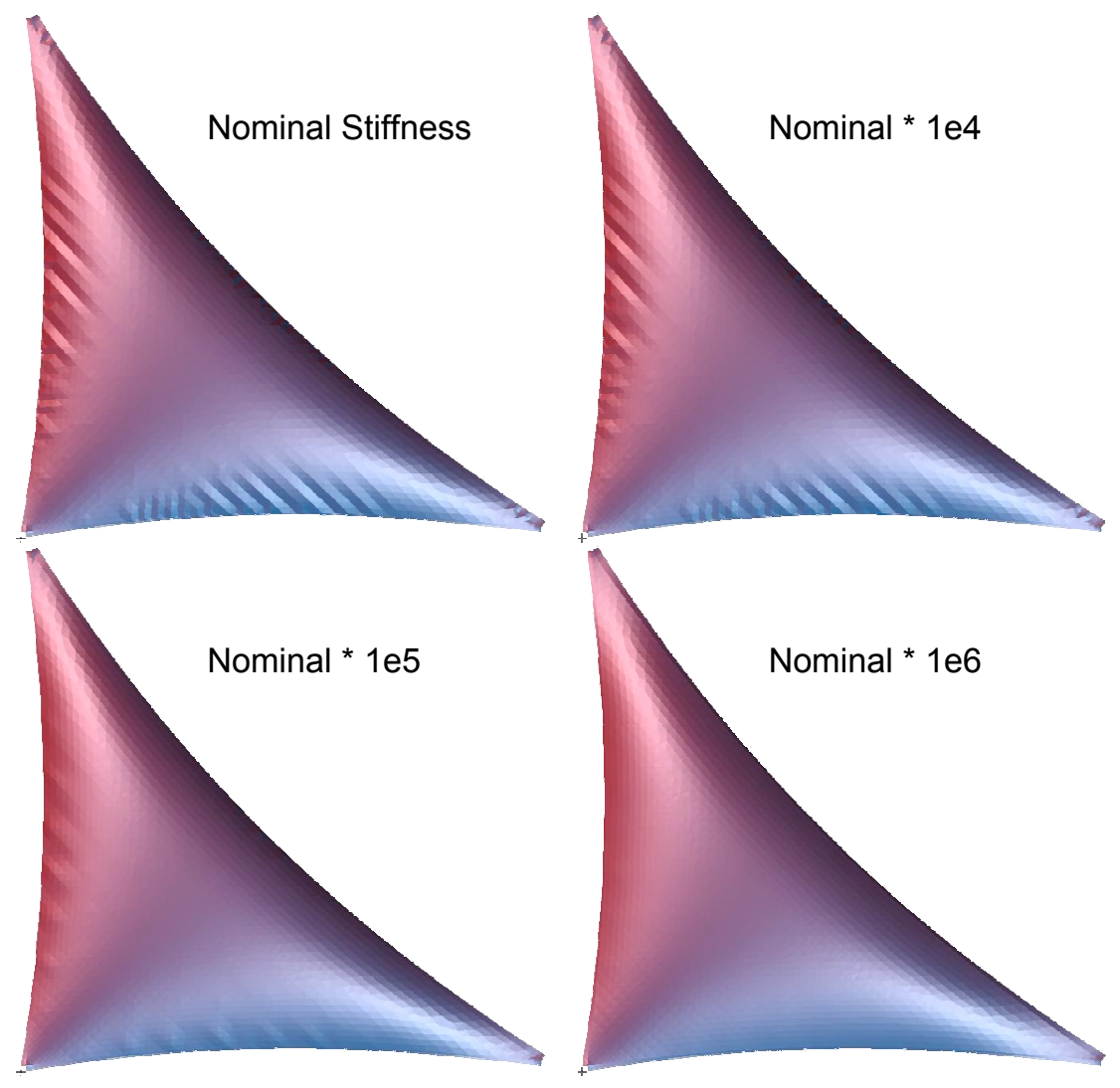

Figure 18. Effect of CP1 Bending Stiffness on sail wrinkle behavior.

inches (the spikes are caused by differences in wrinkle pattern between the two cases). This is a strong indication that the solar sail is indeed dominated by membrane behavior, which means that the deformation is governed by tension and mass and not modulus.

The bending stiffness of the CP1 material was varied to an even greater degree than the modulus. The wrinkle depth is estimated to be two orders of magnitude greater than the membrane thickness. The affect of the winkles is similar to folds in a piece of paper, which move material away from the neutral axis and greatly increases the bending stiffness. In this case, the creases in the $\mathrm{CP} 1$ could mean an increase in bending stiffness by a factor of $10^{4}$. To investigate this behavior fully the bending stiffness was varied by up to a factor of $10^{6}$. The dynamic results can be found in Table 3. With an increase in stiffness of $10^{4}$ the maximum

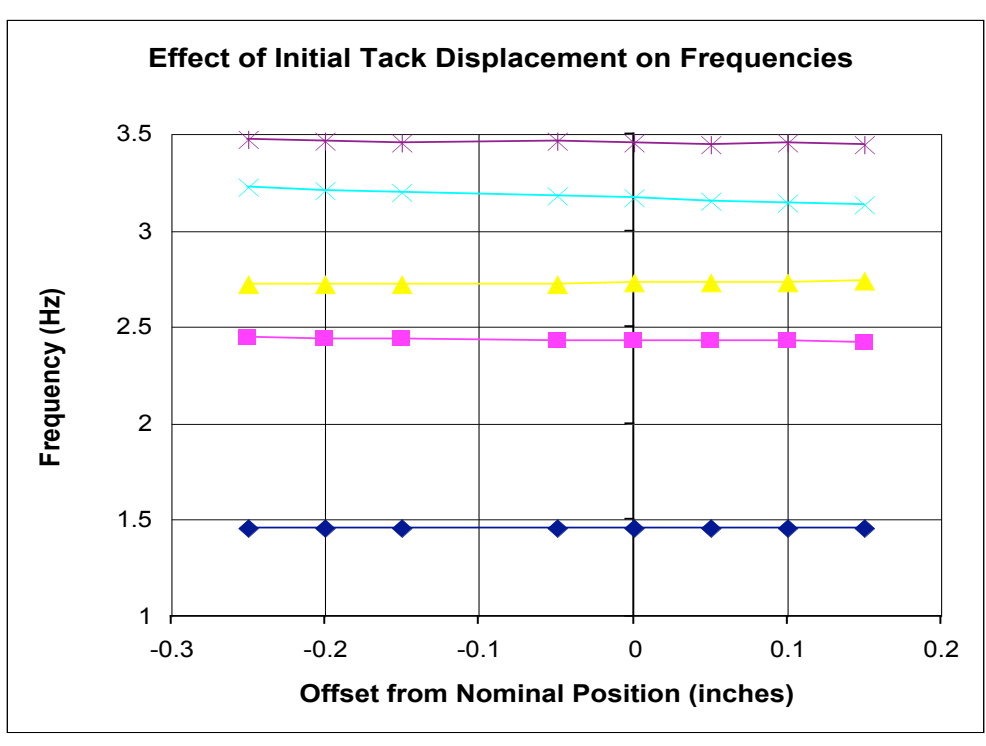

Figure 19. Effect of Tack Line Length on System Frequencies.

American Institute of Aeronautics and Astronautics 
the fifth mode, is only $2 \%$. At $10^{6}$ times nominal the maximum change in frequency is a $14 \%$ increase in the fifth mode. Sail deflection or billow is affected in a similar manner, with minimal effect until the bending stiffness is increased several orders of magnitude. With an increase factor of $10^{4}$ the decrease in deflection is only $2.5 \%$; Figure 17 shows the rest of the data. The most profound change caused by increasing the bending stiffness of the $\mathrm{CP} 1$ is a reduction of the wrinkles found in the sail, as seen in Figure 18.

The length of the tack line was the third major parameter that was studied. Moving the tack line in and out will change the angles that the halyards make with the sail, which in turn varies the stress distribution. Although the tack line length is relatively well known, it was discovered that the sail deflection is very sensitive to the halyard angles. The possible error in the tack line length was

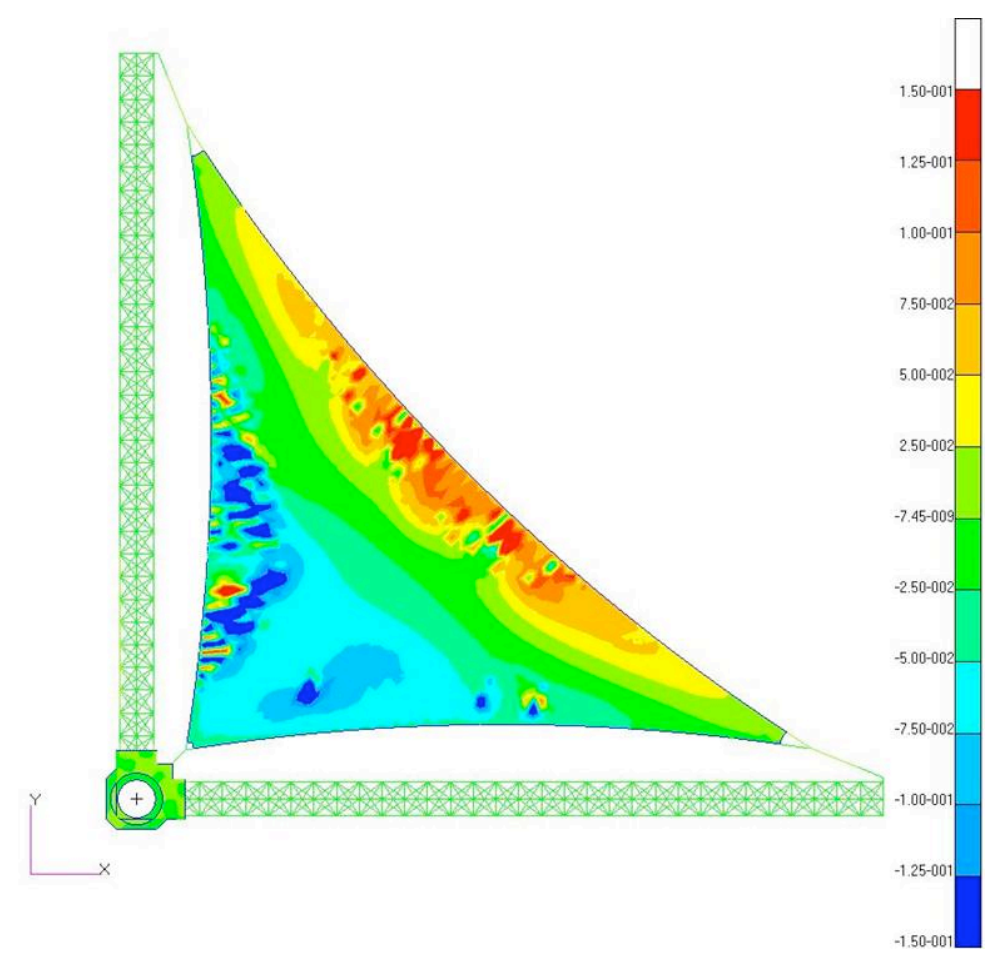

Figure 20. Difference in system deflection shape between the +0.15 inch and -0.15 inch variation in tack line lengths (in inches). estimated to be 0.15 inches. It was

found that there was no appreciable change in the frequencies of the modes for the cases tested (excluding the fourth mode which is the in-plane mode). Figure 19 shows the frequencies as a function of variations in tack line length. It should be noted that when the tack line was varied, the halyard forces were constant, resulting in a slight change in tack line load $(2.52 / 2.58 \mathrm{lbs}$ for the $-0.15 /+0.15$ inch cases). The change in deformation shape was relatively small relative to the overall billow. Comparing the +0.15 inch tack line case and the -0.15 inch tack line case shows that the peak deflection moves outboard as the tack line moves inward. Excluding the peaks (caused by the wrinkles realigning) the net change in billow is approximately 0.15 inches as can be seen in Figure 20.

\section{Concluding Remarks}

Solar sails with ultra-thin membranes and long slender booms present analysis challenges in terms of geometrically nonlinear effects and numerical convergence. A 10 meter quadrant configuration of a solar sail assembly was successfully modeled using finite element analysis with MSC/NASTRAN and ANSYS. Test results were used to validate finite element predictions for the response of the system. Both the static deflection and vibration modes predicted by the finite element analysis codes compared well with the test results.

Our main goal was to develop and verify robust and computationally efficient models for ultralightweight solar sail structures and to make accurate predictions for solar sails that cannot be ground tested. Similar approaches are now being used with sails twice the size.

\section{Acknowledgements}

The work described in this paper was funded in whole or in part by the In-Space Propulsion Technology Program, which is managed by NASA's Science Mission Directorate in Washington, D.C., and implemented by the In-Space Propulsion Technology Office at Marshall Space Flight Center in Huntsville, Ala. The program objective is to develop in-space propulsion technologies that can enable or benefit near and mid-term NASA space science missions by significantly reducing cost, mass or travel times. 


\section{References}

1. J. Wright, Space Sailing, Taylor and Francis Publishers, 1992.

2. C. R. McInnes, "Solar Sailing: Technology, Dynamics, and Mission Applications," Springer-Praxis Series in Space Science and Technology, 1999.

3. A.B. Chmielewski, "Advanced Concepts," Gossamer Spacecraft: Membrane and Inflatable Structures Technology for Space Applications, Edited by C.H.M. Jenkins, Progress in Astronautics and Aeronautics, Vol. 191, American Institute of Aeronautics and Astronautics, Reston, VA, 2001.

4. B. Taleghani, D. W. Sleight, D.M. Muheim, K. Belvin, and J. T. Wong, "Assessment of Analysis Approaches for Solar Sail Structural Response," $39^{\text {th }}$ AIAA/ ASME/SAE/ASEE Joint Propulsion Conference, Huntsville, AL, AIAA-2003-4796,

5. G. Greschik, and M.M. Mikulas, "Design Study of a Square Solar Sail Architecture," $42^{\text {nd }}$ AIAA/ ASME/ASCE/AHS/ASC Structures, Structural Dynamics, and Materials Conference and Exhibit, Seattle, WA, AIAA-2001-1259.

6. Murphy, D., Murphey, T., and Gierow, P., "Scalable Solar-Sail Subsystem Design Concept," AIAA Journal of Spacecraft and Rockets, Volume 40, No. 4, pp. 539-547, July-August 2003.

7. Murphy, D., Trautt, T., McEachen, M., Messner, D., Laue, G., and Gierow, P., "Progress and Plans for System Demonstration of a Scalable Square Solar Sail," AAS 04-105, $14^{\text {th }}$ AAS/AIAA Space Flight Mechanics Meeting, 2004.

8. MSC/NASTRAN Handbook for Nonlinear Analysis, S.H. Lee, editor, The MacNeal Schwendler Corporation, 1992.

9. MSC.NASTRAN Quick Reference Guide, MSC.Software Corporation, 2001.

10. ANSYS Release 8.1 Documentation Preview, ANSYS, Inc., 2004.

11. Murphy, D., Macy, B., Gaspar, J., "Demonstration of a 10-m Solar Sail System," 45 th AIAA Structures, Structural Dynamics, \& Materials Conference, $5^{\text {th }}$ Gossamer Spacecraft Forum, 2004.

12. Gaspar, J., Mann, T., Behun, V., Macy, B., Barker, P., and Murphy, D., "Testing of a 10-meter Solar Sail Quadrant," $46^{h}$ AIAA Structures, Structural Dynamics, \& Materials Conference, $6^{\text {th }}$ Gossamer Spacecraft Forum, 2005. 